\title{
Brain Changes during Phyletic Dwarfing in Elephants and Hippos
}

\author{
George A. Lyras \\ Department of Geology and Geoenvironment, National and Kapodistrian University of Athens, Athens, Greece
}

\section{Keywords \\ Endocast · Encephalization · Insularity · Fossils}

\begin{abstract}
Of all known insular mammals, hippos and elephants present the extremes of body size decrease, reducing to 4 and a mere $2 \%$ of their ancestral mainland size, respectively. Despite the numerous studies on these taxa, what happens to their relative brain size during phyletic dwarfing is not well known, and results are sometimes conflicting. For example, relative brain size increase has been noted in the Sicilian dwarf elephant, Palaeoloxodon falconeri, whereas relative brain size decrease has been postulated for Malagasy dwarf hippos. Here, I perform an analysis of brain, skull, and body size of 3 insular elephants (Palaeoloxodon "mnaidriensis," $P$. tiliensis, and $P$. falconeri) and 3 insular hippos (Hippopotamus madagascariensis, $H$. lemerlei, and $H$. minor) to address this issue and to test whether relative brain size in phyletic dwarf species can be predicted. The results presented here show that the encephalization of all insular elephants and hippos is higher than that of their continental relatives. $P$. falconeri in particular has an enormous encephalization increase, which has so far not been reported in any other insular mammal. Insular brain size cannot be reliably predicted using ei-
\end{abstract}

ther static allometric or ontogenetic scaling models. The results of this study indicate that insular dwarf species follow brain-body allometric relationships different from the expected patterns seen for their mainland relatives.

(c) 2019 S. Karger AG, Basel

\section{Introduction}

Phyletic dwarfism is a pervasive evolutionary trend among large-sized mammals after successful colonization of an island [Lomolino et al., 2013]. The relative brain size of such phyletic dwarfs has been the subject of several papers. However, to date, no consistent pattern of brain-body scaling in insular phyletic dwarf lineages has been reported. For some taxa (Sicilian elephant, Malagasy hippos, and the Majorcan goat), a significant change in relative brain size during dwarfing was reported, while for others (late Pleistocene Cretan dwarf deer, Candiacervus ropalophorus; late Pleistocene Sardinian dwarf canid, Cynotherium sardous; Holocene insular primates, e.g. Macaca spp.) no such trend could be found [Köhler and Moyà-Solà, 2004; Palombo et al., 2008; Lyras, 2009; Weston and Lister, 2009; Montgomery, 2013; Larramendi and Palombo, 2015]. The small brain size of Homo

\section{KARGER}

(c) 2019 S. Karger AG, Basel 
Fig. 1. The Middle Pleistocene Sicilian dwarf elephant (Palaeoloxodon falconeri) and the Cypriot hippopotamus (Hippopotamus minor) compared to their mainland ancestors. Both dwarf species were the smallest of their kind, with body weights of less than 200 and $150 \mathrm{~kg}$, respectively.

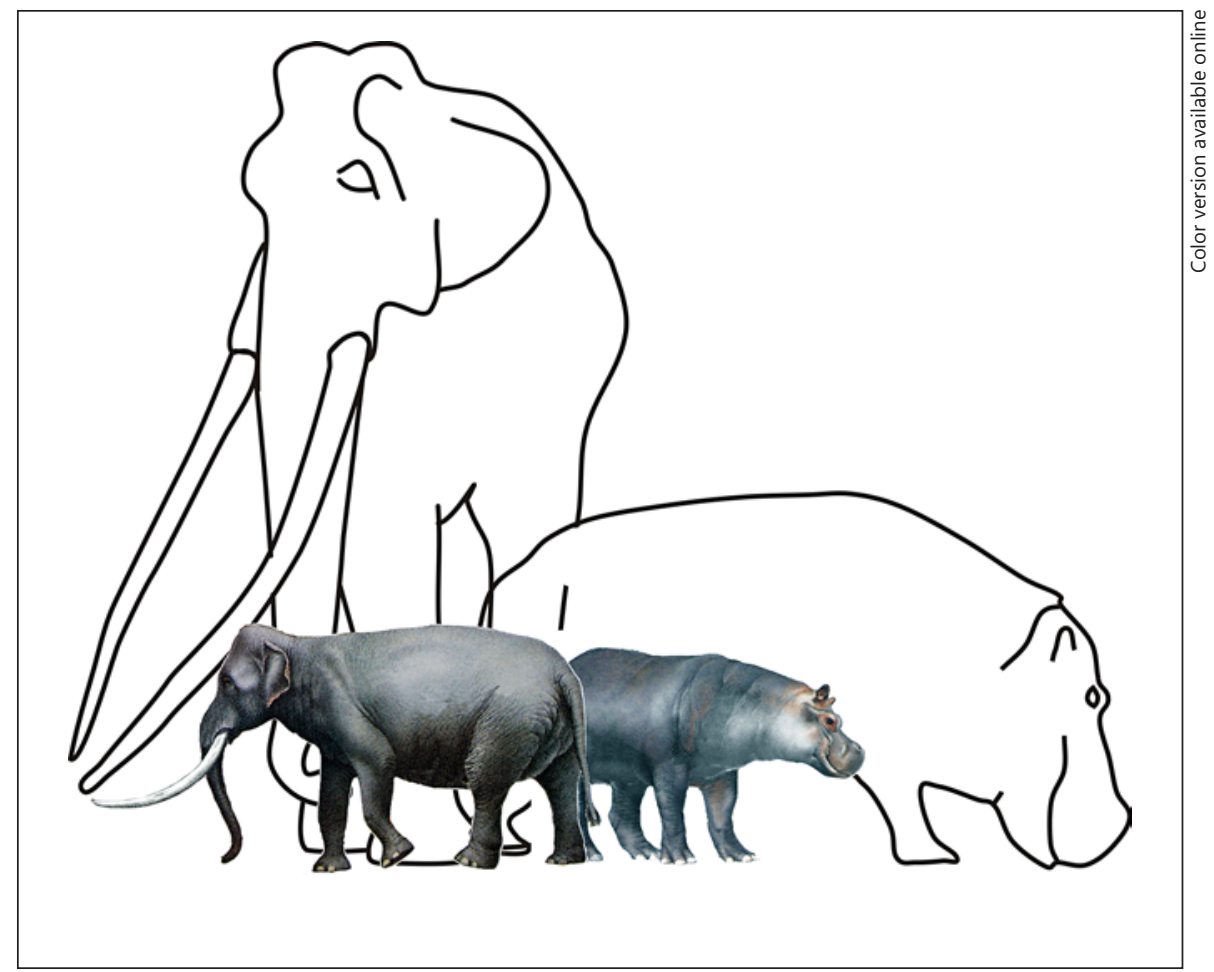

floresiensis (Flores, late Pleistocene) has been explained as the result of phyletic dwarfing as well [e.g. Falk, 2005; Weston and Lister, 2009; Kubo et al., 2013].

Of all known insular mammals, Pleistocene hippopotamuses and elephants present the extremes regarding body size decrease on islands (Fig. 1), reducing to 4 and a mere $2 \%$ of their ancestral mainland size, respectively [Lomolino et al., 2013]. The brain of one of these dwarf elephants, Palaeoloxodon falconeri from Sicily, has been extensively studied and estimated to be relatively larger than that of mainland relatives [Accordi and Palombo, 1971; Palombo and Giovinazzo, 2005; Benoit, 2015; Larramendi and Palombo, 2015]. Palombo and Giovinazzo [2005] attributed its relatively large brain size to paedomorphosis. Regarding dwarf hippopotamuses, only one study exists on the external anatomy of the brain of Malagasy hippos [Anthony, 1948] and one on their relative brain size [Weston and Lister, 2009], both on Malagasy dwarf hippos, Hippopotamus lemerlei and H. madagascariensis. The latter study found a trend of decreasing brain size [Weston and Lister, 2009].

Here, I apply different scaling models to test whether relative brain size of phyletic dwarf species can be predicted. The scaling relationships between brain size and body size are examined here in 4 different ways: (a) with- in the general mammalian trend, (b) within each family, (c) within the static allometry of their contemporary relatives, and (d) within the ontogenetic trend of modern elephants and hippos.

\section{Materials and Methods}

\section{Taxa}

In this contribution, I investigate the brain size changes during phyletic dwarfing in the genera Palaeoloxodon (straight-tusked elephants) and Hippopotamus. For such kind of study, it would have been ideal to utilize specimens from single lineages, from initial colonization by the mainland ancestral species, through stages of insular adaptation, to the ultimate result, the endemic dwarfs. However, no cranial material is known for any single insular lineage of insular hippos or elephants. Therefore, in the absence of such material, I follow the approach of van der Geer et al. [2018] in using dwarf species originating from the same ancestral species but from various islands. These dwarf species represent different degrees of phyletic dwarfing and can therefore be used for modeling the effects of phyletic dwarfing. In particular, I here describe the brain size changes from Palaeoloxodon antiquus (mainland ancestor) to P. "mnaidriensis" (late Pleistocene of Sicily; $17 \%$ of ancestral body mass $[\mathrm{BM}]$ ), to $P$. tiliensis (late Pleistocene of Tilos; $9 \%$ of ancestral BM) and to P. falconeri (middle Pleistocene of Sicily; $2 \%$ of ancestral BM). For hippopotamuses, I investigate the changes from Hippopotamus amphibius (mainland relative) to 
H. madagascariensis and H. lemerlei (?late Pleistocene to Holocene of Madagascar; $25 \%$ of ancestral BM), to $H$. minor (Pleistocene of Cyprus; $4 \%$ of ancestral BM) (degree of BM reductions from Lomolino et al. [2013]). It is important to emphasize here that the focal species do not represent stages of an actual evolutionary sequence. The 2 Sicilian dwarf elephants ( $P$. "mnaidriensis" and $P$. falconeri) resulted from 2 independent colonizations, and the Malagasy hippopotamuses (H. madagascariensis and H. lemerlei) have no direct relation to the Cypriot hippopotamus (H. minor) [van der Geer et al., 2010]. In other words, the species are here treated as model stages, illustrating different degrees of phyletic dwarfing.

In order to put the observations on insular elephants and hippos in a broader context, I compare them with 4 other insular dwarf species for which brain size data are available: the Balearic goat Myotragus balearicus, the Cretan deer C. ropalophorus, the Sardinian $\operatorname{dog} C$. sardous, and the small hominid from Flores $H$. floresiensis.

The relative brain size of Myotragus is evaluated using 2 mainland Miocene Caprinae (Urmiatherium and Plesiaddax) and 1 mainland Miocene Bovinae (Miotragocerus). I compare Myotragus with Miocene bovids because this lineage became isolated at the end of the Miocene, more than 5 million years ago [Bover et al., 2008]. Comparing with Miocene, and not Pleistocene taxa, is crucial as the relative brain size of ungulates increased over time [Jerison, 1973]. Moreover, in order to better appreciate the data from the Miocene taxa, I include 4 living taxa as well (Budorcas, Oreamnos, Rupicapra, and Capra). The brain of C. sardous is compared with 3 mainland wolf-like Caninae: Xenocyon lycaonoides, a middle Pleistocene canid which has been proposed as the mainland relative of Cynotherium [Lyras et al., 2006], and 2 related living Caninae, the wolf (Canis lupus) and the African hunting dog (Lycaon pictus). The relative brain size of C. ropalophorus is evaluated using 2 living Cervinae: the fallow deer (D. dama) and the red deer (Cervus elaphus). Fallow deer is the living relative of Candiacervus [van der Geer, 2018]. Candiacervus is a late Pleistocene species, and hence it is feasible to compare it with living taxa. Finally, I compare the relative brain size of $H$. floresiensis with Homo erectus, a mainland hominid that could be its mainland relative [van den Bergh et al., 2016].

\section{Taxonomic Framework}

I follow Boisserie [2005] in considering the mainland pygmy hippopotamus of West Africa as a member of the genus Choeropsis and not of Hexaprotodon. I follow Stuenes [1989] in referring the Malagasy dwarf hippos to Hippopotamus. Although I am aware of the fact that the names $H$. lemerlei and $H$. madagascariensis should be taxonomically revised [Goodman and Jungers, 2014], and that the latter species is sometimes referred to as H. guldbergi [Fovet et al., 2011], I choose to use the species names and their description as defined by Stuenes [1989] in order to be consistent with the current use of these names. The Cypriot dwarf hippo is often placed in a genus of his own (Phanourios), described by Boekschoten and Sondaar [1972]. However, since it descended directly from Hippopotamus [Boekschoten and Sondaar, 1972; Houtekamer and Sondaar, 1979; Boisserie, 2005], I here treat it as a member of Hippopotamus, following van der Geer et al. [2010].

Palaeoloxodon mnaidriensis is a dwarf elephant species of Malta. The same name has been extensively used for the larger-sized dwarf elephant of Sicily. However, the specific status of the Sicilian material (Puntali Cave) has been questioned [Ferreti, 2008; Her- ridge, 2010; van der Geer et al., 2014], and probably a new species should be erected to accommodate the Sicilian material (Palaeoloxodon sp. nov. in Herridge [2010]). I here list it as Palaeoloxodon "mnaidriensis" awaiting taxonomic revision.

\section{Endocranial Volumes}

I measured the brain volume of the following skulls (Table 1): 2 Palaeoloxodon "mnaidrienisis" (MGG, see Table 1 for institutional abbreviations), 1 P. tiliensis (AMPG), 1 H. minor (MUU), 5 Asian elephants (Elephas maximus) (AMNH), 7 common hippopotamuses (H. amphibius), and 5 pygmy hippopotamuses (Choeropsis liberiensis) (AMNH, AMPG, MFN), and 2 C. ropalophorus (AMPG). I also measured the endocranial volumes (EV) as well as the overall skull volume (see below) of 26 skulls from 11 orders of contemporary placental mammals. EV were measured with silica balls. In addition, I measured the volume of 2 natural endocranial casts: Urmiatherium intermedium and Plesiaddax depereti (NHM). The latter 2 endocasts were scanned with a NextEngine 3D laser scanner. The acquired scans were converted into closed mesh models and were imported in Blender for calculating their volume. Blender is an open source 3D computer graphics software used in creative arts and for scientific analysis and visualization [Pyka et al., 2010; Jorstad et al., 2015].

Data on the brain size of the following species were taken from the literature: P. antiquus [Osborn, 1931; Accordi and Palombo, 1971], P. falconeri [Accordi and Palombo, 1971], Mammuthus meridionalis and $M$. primigenius [Benoit, 2015], $H$. lemerlei and $H$. madagascariensis [Weston and Lister, 2009], M. balearicus and Miotragocerus gaudryi [Köhler and Moyà-Solà, 2004], H. erectus and H. floresiensis [Weston and Lister, 2009; Kubo et al., 2013], X. lycaonoides, and C. sardous [Lyras, 2009]. Brain sizes of living mammals (other than hippos and elephants) were taken from Pérez-Barbería and Gordon [2005]; Boddy et al. [2012], and Stankwich and Romero [2016].

Some studies estimate the mass of the brain by multiplying the volume of the endocast with the specific gravity of the brain (published densities range from 1,027 to $1,100 \mathrm{~g} / \mathrm{cm}^{3}$, see Cuff et al. [2017]). Jerison [1973] indicated that the difference between brain weight and EV is smaller than the order of magnitude of the errors of measurement. He therefore suggested that one should avoid making adjustments in endocast volume and consider the volume of the endocast in cubic centimeter to be the same as the weight of the brain in gram. This is in general valid, but in large-brained mammals such as cetaceans and elephants, the EV value is larger than the corresponding actual brain weight in grams [Osborn, 1931; Marino, 1999; Shoshani et al., 2006; Benoit, 2015]. The underlying reason is that a brain endocast is not only a cast of the actual brain tissues but also comprises the tissues surrounding the brain [Bauchot and Stephan, 1967; Macrini et al., 2007]. The degree of the difference between EV and actual brain size increases with brain size [Edinger, 1948; Röhrs and Ebinger, 2001; Benoit, 2015]. Therefore, whenever a comparison involves endocasts and actual brains, I convert the EV into brain mass (brM), using the equation of Benoit [2015], according to which brM = $(0.8877 \mathrm{EV})-2.9408$.

\section{Body Masses}

BM estimations of fossil species are from Weston and Lister [2009], Lomolino et al. [2013], and van der Geer et al. [2013] except for M. gaudryi, P. depereti, and U. intermedium, which were 
Table 1. Specimens used in this study

\begin{tabular}{|c|c|c|c|c|}
\hline Species & Specimen & $\begin{array}{l}\text { Age, } \\
\text { years }\end{array}$ & $\begin{array}{l}\text { Endocranial } \\
\text { volume, } \mathrm{cm}^{3}\end{array}$ & $\begin{array}{l}\text { Skull } \\
\text { volume, } \mathrm{cm}^{3}\end{array}$ \\
\hline Elephas maximus & AMNH(M) 70266 & 3 & 2,900 & 8,588 \\
\hline Elephas maximus & AMNH(M) 119674 & 6 & 4,680 & 12,544 \\
\hline Elephas maximus & AMNH(M) 14117 & 5 & 4,460 & 14,041 \\
\hline Elephas maximus & AMNH(M) 39086 & 14 & 5,140 & 23,165 \\
\hline Elephas maximus & AMNH(M) 246135 & 35 & 5,120 & 91,476 \\
\hline Elephas maximus & AMNH(M) 34087 & 6 & 3,960 & 12,396 \\
\hline Choeropsis liberiensis & AMNH(M) 148452 & 33 & 350 & 2,605 \\
\hline Choeropsis liberiensis & AMNH(M) 2425 & 5.5 & 215 & 958 \\
\hline Choeropsis liberiensis & AMNH(M) 185383 & 0.5 & 120 & 281 \\
\hline Choeropsis liberiensis & AMNH(M) 146849 & 33 & 320 & 1,900 \\
\hline Choeropsis liberiensis & MFN ZMB 46517 & 0.5 & 110 & 147 \\
\hline Hippopotamus amphibius & AMNH (M) 54248 & 15 & 700 & 6,868 \\
\hline Hippopotamus amphibius & MFN ZMB 76583 & 6.5 & 650 & 4,710 \\
\hline Hippopotamus amphibius & AMNH(M) 54249 & 10 & 670 & 5,084 \\
\hline Hippopotamus amphibius & AMNH(M) 90230 & 9 & 740 & 8,622 \\
\hline Hippopotamus amphibius & AMPG H.a.2 & 27 & 980 & 16,034 \\
\hline Hippopotamus amphibius & MFN ZMB 76582 & 1.5 & 480 & 2,075 \\
\hline Hippopotamus amphibius & MFN ZMB 44187 & 0.5 & 230 & 5,480 \\
\hline Palaeoloxodon antiquus & AMNH 22634 & adult & 6,807 & 184,822 \\
\hline Palaeoloxodon "mnaidriensis" & MGG skull n.1 & adult & & 40,544 \\
\hline Palaeoloxodon "mnaidriensis" & MGG skull n.9 & adult & 4,260 & \\
\hline Palaeoloxodon "mnaidriensis" & MGG skull n.13 & adult & 4,300 & \\
\hline Palaeoloxodon tiliensis & AMPG T189/96 & adult & 3,000 & \\
\hline Hippopotamus lemerlei & AMPG 939 & adult & 410 & 3,606 \\
\hline Hippopotamus lemerlei & MNHN Mad 1076 & adult & 345 & 2,105 \\
\hline Hippopotamus lemerlei & MNHN Mad 7914 & adult & 390 & 3,041 \\
\hline Hippopotamus madagascariensis & MNHN Mad 7352 & adult & 450 & 2,627 \\
\hline Hippopotamus madagascariensis & MNHN Mad 1069 & adult & 460 & 2,767 \\
\hline Hippopotamus madagascariensis & MFN MBMa 42517 & adult & & 3,175 \\
\hline Hippopotamus minor & MUU dkm c & adult & 218 & 1,057 \\
\hline Candiacervus ropalophorus & AMPG Ge nn & adult & 133 & \\
\hline Candiacervus ropalophorus & AMPG Re 6984 & adult & 137 & \\
\hline Urmiatherium intermedium & NHM M.nn & adult & 185 & \\
\hline Plesiaddax depereti & NHM M.nn & adult & 161 & \\
\hline
\end{tabular}

Institutional Abbreviations: AMNH, American Museum of Natural History, New York, USA; AMPG, Museum of Palaeontology and Geology, University of Athens, Greece; MGG: Museo Geologico G.G. Gemmellaro, Palermo, Italy; MFN, Museum für Naturkunde, Berlin, Germany; MNHN, Muséum National d'Histoire Naturelle, Paris, France; MUU, Museum of the University of Utrecht, Utrecht, the Netherlands; NHM, Natural History Museum, London, UK.

here estimated with the width of the occipital condyles, using the equation of Köhler and Moyà-Solà [2014] and measurements from Spassov and Geraads [2004] and Lazaridis et al. [2017]. Mean BM data of extant species are from Smith et al. [2003], except for those of adult Loxodonta africana and E. maximus individuals, which were taken from Shoshani et al. [2006]. Since to my knowledge no similar study exists for hippos and since most museum specimens of large-sized mammals lack associated body weight data, I followed an indirect approach by reconstructing their BM using growth curves. To this goal, BM of adult $H$. amphibius were reconstructed following Weston and Lister [2009], using the curves of Martin [2005] representing the relationship between age and body weight. Similarly, the BM of juvenile $H$. amphibius and E. maximus individuals were reconstructed using the curves of Martin [2005] and Kurt and Kumarasinghe [1998], respectively.

\section{Skull Volumes}

For further investigating the issue of relative brain size, I additionally use skull size instead of body size. Weston and Lister [2009] used skull size as a proxy for body size in their study of relative brain size in dwarf hippos. Van der Geer et al. [2018] noted that skull volume and body size scale almost isometrically within adult terrestrial placental mammals, thus confirming that skull 


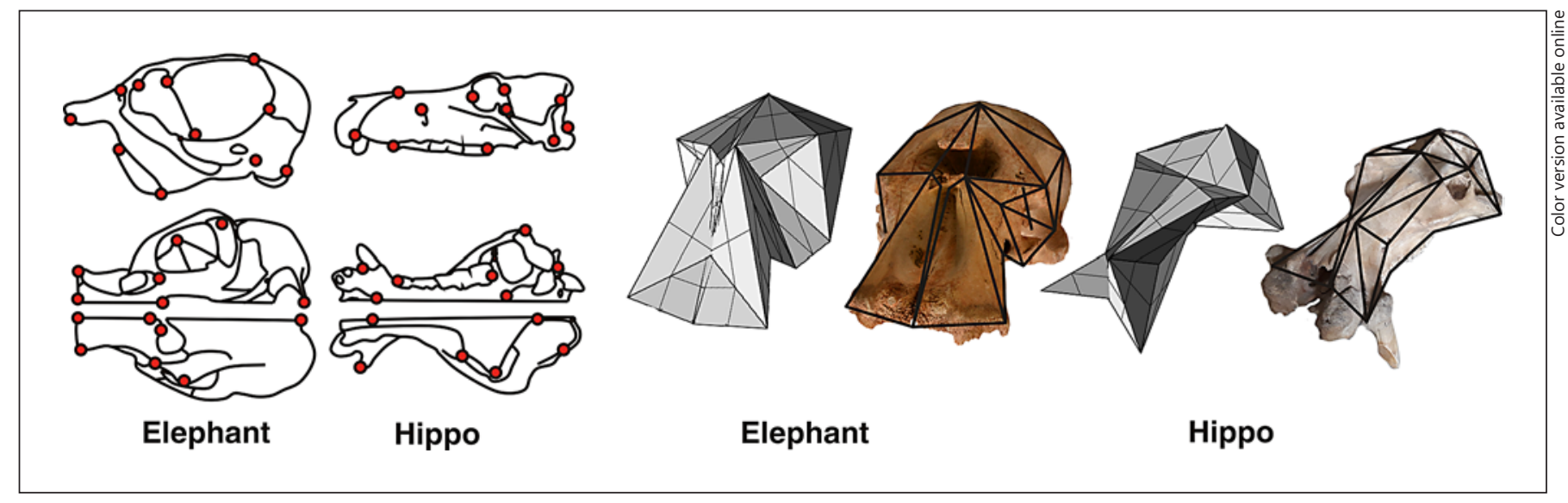

Fig. 2. The landmarks used to estimate skull volume in elephants and hippos, and 2 examples of the finalized 3D meshes.

size instead of body size can be used as well in studies of relative brain size. According to the same study, the ontogenetic regressions of $H$. amphibius and E. maximus have major axis slopes for the log-transformed variables of 0.9221 and 1.2262 , respectively. Although elephants do not follow the general relationship between skull and body size noted in mammals, the approach of using the skull volume is applied here as well. The advantage of using skull volume over estimations of body size from growth curves is that both skull size and endocranial capacity can be accurately measured for the same individuals. This is particularly useful when dealing with individuals of the same species.

I digitized a series of 5 fossil and 6 extant elephant specimens, 7 fossil, and 12 extant hippo specimens, and a representative sample of 26 skulls from 11 orders of placental mammals (the data are always taken on the same skull I measured the brain volume). I calculated their volume of $3 \mathrm{D}$ polygon meshes following the method of van der Geer et al. [2018]. The polygon meshes are based on a set of 17 landmarks on the left side of each skull and are designed as a series of triangles (Fig. 2). These landmarks were captured with a MicroScribe on the same skull for which I measured EV. The triangular meshes were created using Rhino3D software.

One particular specimen of $P$. antiquus (AMNH 22634), currently curated in New York, was badly damaged before it was sent from Italy to the United States [Osborn, 1931]. Although Osborn claims that the restoration was sufficiently accurate, Maglio [1973] warns that it presents many mistakes. The specimen is indeed inappropriate for morphological studies. However, since its restoration was based on measurements that were taken prior to the damage, it still provides a very good indication of the actual size of the original, intact specimen.

\section{Brain versus Body Mass}

Because the size of the brain scales allometrically with that of the body, Jerison [1973] proposed the use of encephalization quotient (EQ), which is the observed brain size versus the expected brain size for a mammal of the same BM. The expected brain size is calculated by regressions of brM versus BM that characterize the general trend among mammals. Here I estimate the EQ using the regression of Manger [2006], because this regression excludes cetaceans and primates.

The Brain of Insular Elephants and Hippos
Ontogeny and Age Determination of Hippopotamuses and Elephants

While Hippopotamus is a living taxon, no palaeoloxodontine elephant is living today. Moreover, there are no known endocasts of juvenile $P$. antiquus. Therefore, a living elephant, the Asian E. maximus, is used here as a proxy species for the ontogeny of Palaeoloxodon. Both taxa are morphologically similar, and till recently, Palaeoloxodon was subsumed into the genus Elephas [Maglio, 1973; Shoshani et al., 2007]. It should be noted, however, that recent genetic studies indicate a closer phylogenetic relationship between $\mathrm{Pa}$ laeoloxodon and Loxodonta [Meyer et al., 2017; Palkopoulou et al., 2018].

Individual age estimation of hippos is based on Laws [1968] for Hippopotamus and Weston [1998] for Choeropsis. Hippos are here considered adult when their third lower molar is completely erupted (represented by Laws stage XIII). Age estimation for E. maximus is based on dental eruption and wear patterns following Roth [1984] and Roth and Shoshani [1988].

\section{Results}

For brain size and BM data in Palaeoloxodon, and Hippopotamus and Choeropsis, see Tables 2 and 3, respectively. In particular, the brains of P. falconeri $(1,800$ $\mathrm{cm}^{3}$, estimated to weight $\left.1,595 \mathrm{~g}\right)$, of $P$. tiliensis $(3,000$ $\mathrm{cm}^{3}$, estimated as $\left.2,660 \mathrm{~g}\right)$ and of $P$. "mnaidriensis" $(4,280$ $\mathrm{cm}^{3}$ estimated as $3,796 \mathrm{~g}$ ) (Table 2) are considerably smaller than the brain of living elephants (range 4,000$6,500 \mathrm{~g}$ in Shoshani et al. [2006]). The slope of intraspecific scaling of Palaeoloxodon during dwarfing is 0.39 . The EV of Malagasy hippos has been measured by Weston and Lister [2009]. The average brain size of $H$. madagascariensis is $421 \mathrm{~cm}^{3}$ (estimated as $370 \mathrm{~g}$ ) and that of $\mathrm{H}$. lemerlei is $380 \mathrm{~cm}^{3}$ (estimated as $334 \mathrm{~g}$ ). H. minor has a brain size of $218 \mathrm{~cm}^{3}$ (estimated as $190 \mathrm{~g}$ ) (Table 3). 
Table 2. Metric data of Palaeoloxodon species for body and brain size

\begin{tabular}{|c|c|c|c|c|c|c|}
\hline Species & $\mathrm{BM}, \mathrm{kg}$ & $\begin{array}{l}\text { Observed endocranial } \\
\text { capacity, } \mathrm{cm}^{3}\end{array}$ & $\begin{array}{l}\text { Estimated } \\
\text { brM }^{1}, \mathrm{~g}\end{array}$ & $\begin{array}{l}\text { Expected brM for } \\
\text { the average extant } \\
\text { mammal of that } \\
\mathrm{BM}^{2}, \mathrm{~g}\end{array}$ & $\begin{array}{l}\text { Expected brM using } \\
\text { the static allometry } \\
\text { of modern } \\
\text { elephants }^{3}, g\end{array}$ & $\begin{array}{l}\text { Expected endocranial } \\
\text { capacity using the } \\
\text { ontogenetic allometry } \\
\text { of E. maximus }{ }^{4} \mathrm{~cm}^{3}\end{array}$ \\
\hline P. antiquus & $7,976^{5}$ & $\begin{array}{l}9,000^{6}-6,807^{7} \\
\text { [average } 7,903 \text { ] }\end{array}$ & 7,012 & 6,227 & & \\
\hline P. "mnaidriensis" & $1,380^{5}$ & $\begin{array}{l}4,260-4,300^{8} \\
\text { [average } 4,280 \text { ] }\end{array}$ & 3,796 & 1,767 & 4,335 & 4,353 \\
\hline P. falconeri & $189^{5}$ & $1,800^{10}$ & 1,595 & 423 & 4,101 & 2,397 \\
\hline
\end{tabular}

${ }^{1}$ Brain mass (brM) is calculated from endocranial volume (EV) using the method of Benoit [2013]. ${ }^{2}$ Expected brM for the average living mammal of that body mass (BM) using the equation of Manger [2006]. ${ }^{3}$ Using the allometric relationship between brM and BM in modern elephants. ${ }^{4}$ Using an allometric relationship between EV and BM in E. maximus. ${ }^{5}$ BM from Lomolino et al. [2013]. ${ }^{6}$ Data from Maccagno [1962]. ${ }^{7}$ Data from Osborn [1931]. ${ }^{8}$ EV of 2 MGG specimens (skull n.3 and n.7). ${ }^{9}$ EV of AMPG T189/96. ${ }^{10}$ Data from Accordi and Palombo [1971].

Table 3. Metric data of hippopotamid species on body and brain size

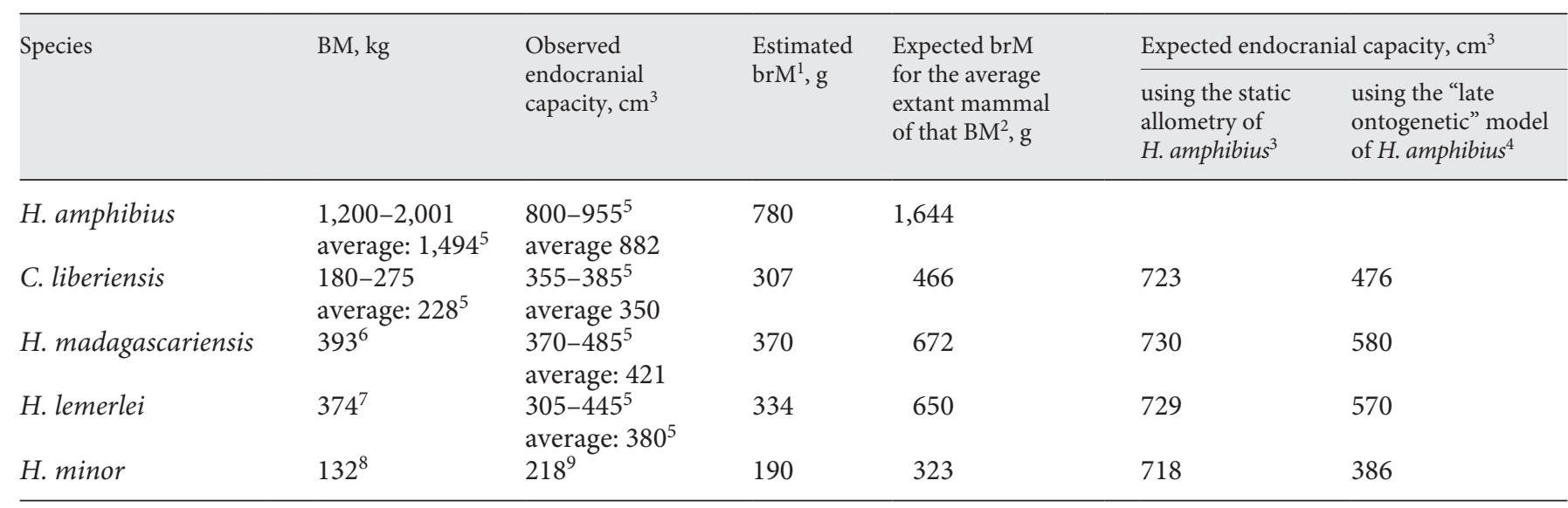

${ }^{1}$ Brain mass (brM) is calculated from endocranial volume (EV) using the method of Benoit [2013]. ${ }^{2}$ Expected brM for the average living mammal of that body mass (BM) using the equation of Manger [2006]. ${ }^{3}$ Using the allometric relationship between EV and estimated BM in hippos. ${ }^{4}$ Using the "late ontogenetic" relationship between endocranial capacity and estimated BM in H. amphibius of Weston and Lister [2009, their $\mathrm{S}_{\mathrm{i}}$ Fig. 4]. ${ }^{5}$ Data from Weston and Lister [2009]. ${ }^{6}$ Weston and Lister [2009] indicate an average BM of $374 \mathrm{~kg}$ (based on cranial size) and a range of $274-393 \mathrm{~kg}$ (based on postcrania). ${ }^{7}$ Weston and Lister [2009] indicate an average BM 393 $\mathrm{kg}$ (based on cranial size) and a range of $310-642 \mathrm{~kg}$ (based on postcrania). ${ }^{8}$ Data from Lomolino et al. [2013]. ${ }^{9} \mathrm{EV}$ of MUU dkm c.

The slope of intraspecific scaling of Hippopotamus during dwarfing is 0.58 .

\section{Brain Scaling in Elephants and Hippos within the General Mammalian Trend}

Dwarf hippos have relatively smaller brains than the average mammal of the same size (Fig. 3a). In contrast, dwarf elephants are relatively large-brained animals. Particularly the small Sicilian dwarf, P. falconeri, has a rela- tive brain size that plots considerably higher than that of most mammals of comparable body size.

The Manger EQ in insular hippos is low (ranging from 0.48 to 0.58 ). Continental hippos have low EQ as well. The Manger EQ of H. amphibus is 0.41. Slightly different EQ values are produced when using other equations, such as those of Jerison [1973] and Martin [1981]. Nevertheless, the differences in EQ between island and mainland forms are comparable. On the contrary to hippos, dwarf ele- 


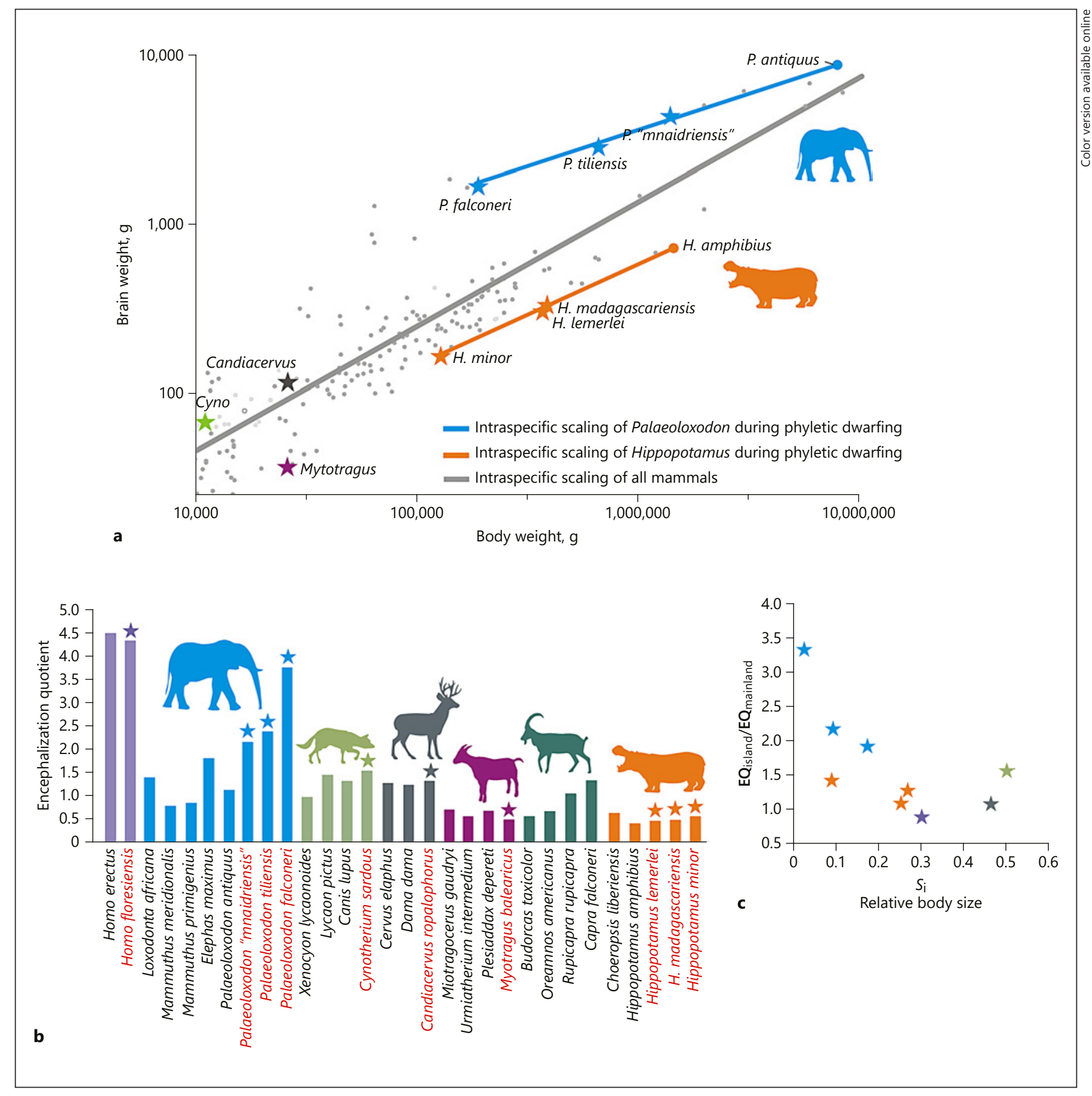

Fig. 3. Relative brain size of insular phylogenetic dwarfs compared to other mammals. a Plot of brain weight versus body weight and regressions of Palaeoloxodon and Hippopotamus as well as for "all" mammals (excluding Cetacea and Primates). The regression line of all mammals is drawn from Manger [2006]. b Bar graph of en- cephalization quotients (EQ) of various insular mammals (indicated by asterisks) and of their mainland relatives. c The EQ of insular mammals plotted against their relative body size (body mass of insular species vs. mainland ancestral form). 


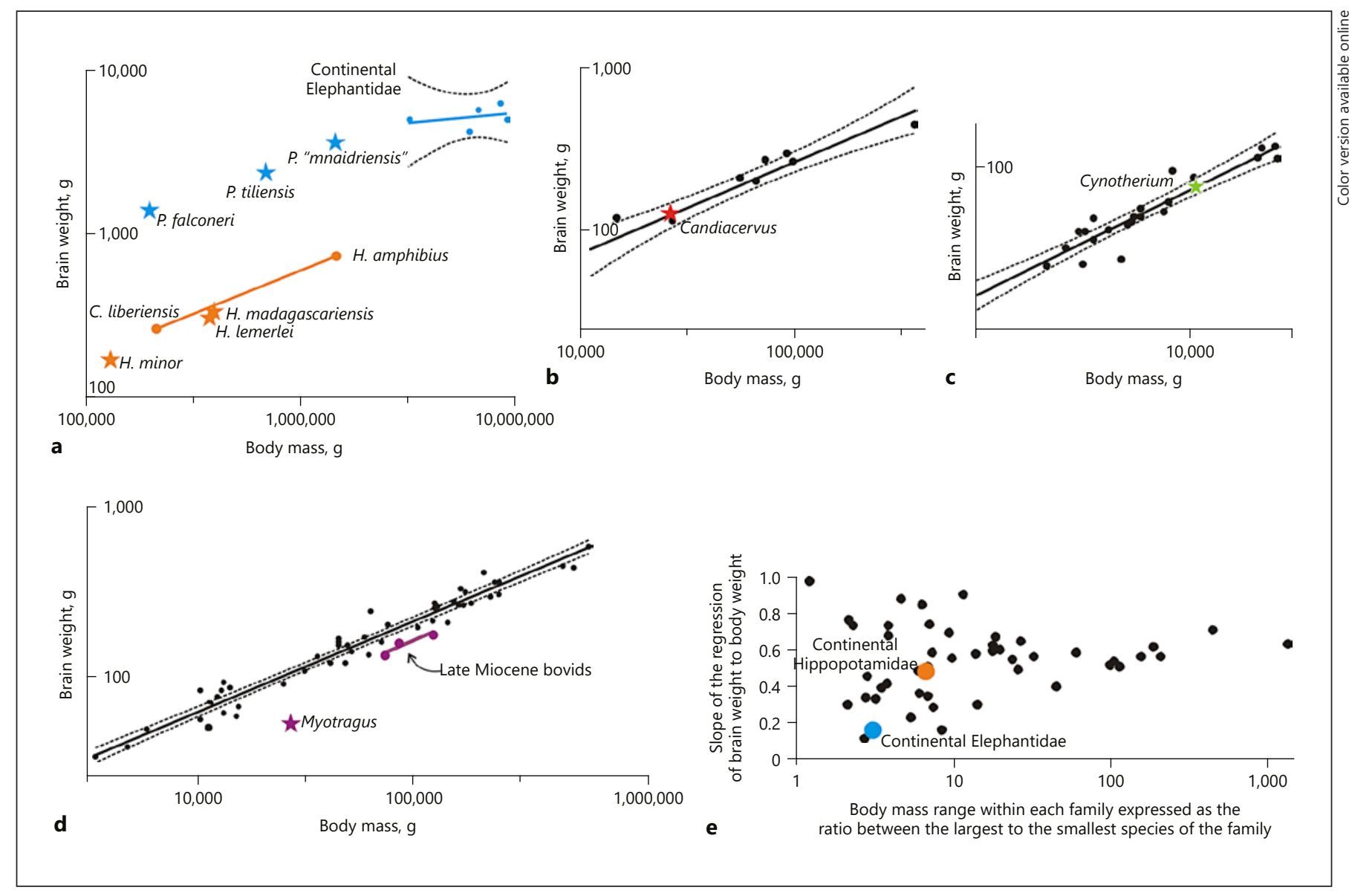

Fig. 4. Relative brain size of insular phylogenetic dwarfs compared among their families. Plot of brain weight versus body weight and regressions of Elephantidae and Hippopotamidae (a); Cervidae (b); Canidae (c), and Bovidae (d). e Slope of the regression of the brain weight to body weight of various mammalian families against the body mass variation within each family. The regression lines and the calculation of the slopes for each family were drawn following the least square method and with data from the literature (see Materials and Methods). Asterisks indicate insular phylogenetic dwarfs. phants have high EQ. The Manger EQ rises from 1.12 in $P$. antiquus to 2.14 in $P$. "mnaidriensis," 2.40 in $P$. tiliensis and 3.75 in P. falconeri (Fig. 3b). It appears that the larger the difference in $\mathrm{BM}$ between insular and mainland ancestral species, the more their EQ differs (Fig. 3c).

\section{Brain Scaling in Elephants and Hippos within Each \\ Family}

An alternative approach is to examine the brain of phylogenetic dwarfs within the allometric scaling of Elephantidae and Hippopotamidae, respectively (Fig. 4a). The allometric relationship between brM and BM for Elephantidae is here calculated based on 2 contemporary species (E. maximus, L. africana) and 3 mainland Pleistocene species ( $P$. antiquus, $M$. primigenius, $M$. meridiona- lis). The slope of the allometric trend in elephants then is 0.138 . Such a value is relatively low, though still within the range of other mammalian families, which range between 0.11 and 0.97 (Fig. 4e). The brain of $P$. "mnaidriensis" is slightly smaller than what is predicted by the allometric trend of Elephantidae, whereas the brain of $P$. falconeri is considerably smaller than what is predicted by the allometric trend of Elephantidae.

The allometric relationship for Hippopotamidae is here calculated based on the 2 contemporary species $(H$. amphibius, C. liberiensis). The allometric relationship between brM and BM for Hippopotamidae is 0.48. All 3 insular hippos have a slightly smaller brain than what is predicted by the 2 modern mainland hippos. 


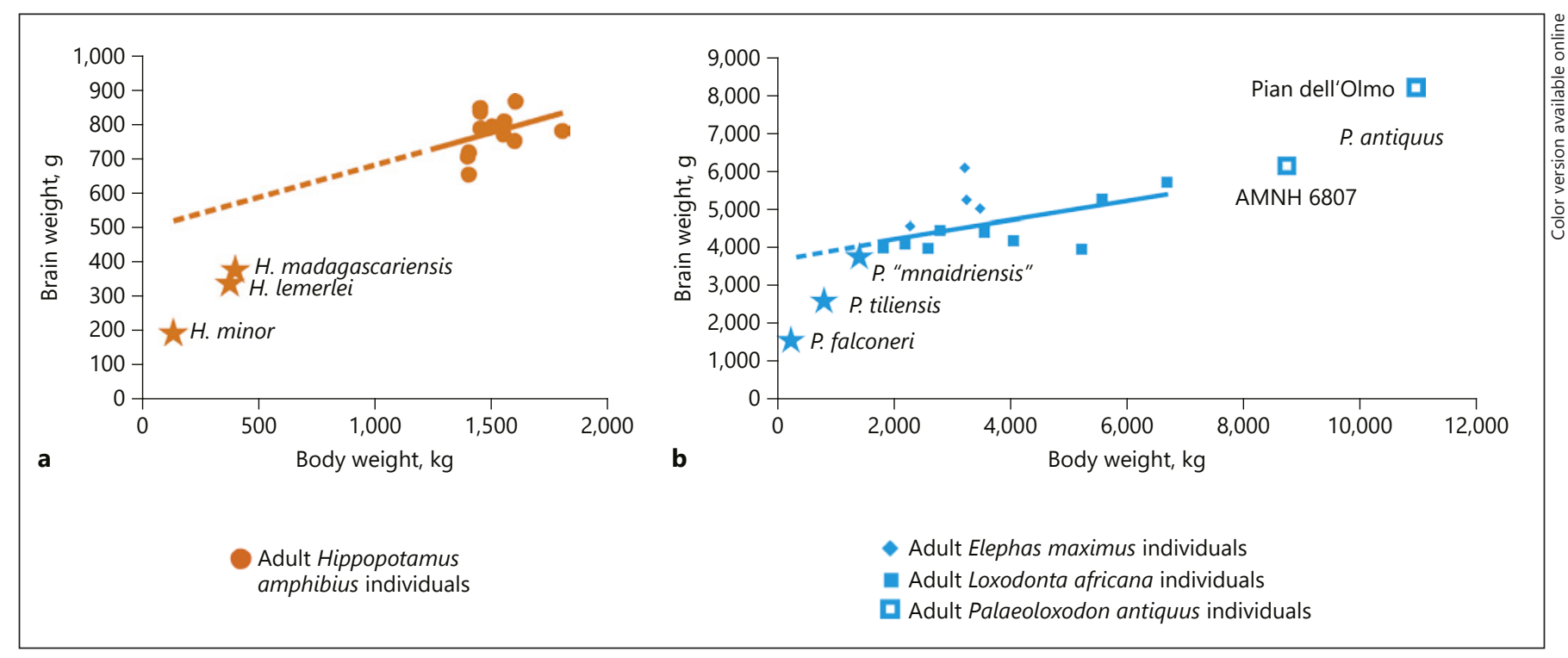

Fig. 5. Scatter plots of brain weight versus body weight of adult Hippopotamus amphibius, Loxodonta africana, Elephas maximus, and Palaeoloxodon antiquus individuals and regression of intra- specific scaling in Hippopotamus amphibius and living elephants. Asterisks indicate the position of insular phylogenetic dwarfs.

cording to the same trend line, an elephant with the BM of $P$. "mnaidriensis" $(1,380 \mathrm{~kg})$ is predicted to have a brain of $4,335 \mathrm{~g}\left(4,887 \mathrm{~cm}^{3}\right)$, which is closer to the observed one.

\section{Within the Intraspecific Ontogenetic Scaling Model of} Contemporary Relatives

A fourth approach is to examine the ontogenetic trajectory of their closest living relatives. Figure 6 shows a scatter plot of the EV against BM (Fig. 6a) and against the skull volume (Fig. 6b) of adult fossil and contemporary elephants and hippos of different ontogenetic stages. The allometric relationship between endocranial capacity (EV) and BM in E. maximus was based on data of 6 individuals (Table 1). The equation is $\mathrm{EV}=497.55(\mathrm{BM})^{0.3}$ (EV in $\mathrm{cm}^{3}$ and $\mathrm{BM}$ in $\mathrm{kg}$ ). The "late ontogenetic" relationship in H. amphibius is from Weston and Lister [2009, their supporting information Fig. 4]. The skull volume of adult elephants is several times larger than their corresponding EV. For example, the skull of $\operatorname{AMNH}(\mathrm{M})$ 246135 (E. maximus) is 17 times the size of its endocranial cavity. Insular elephants appear to have much lower skull/endocast size ratios. The skull volume of Palaeoloxodon "mnaidriensis" is approximately 8 times the size of its EV, while that of $P$. falconeri is only double its EV. The $\mathrm{EV}$ of $P$. "mnaidriensis" is thus comparable to that of a 5-year-old juvenile male E. maximus (AMNH(M) 14117), which according to the growth curves of Kurt and Kuma- 


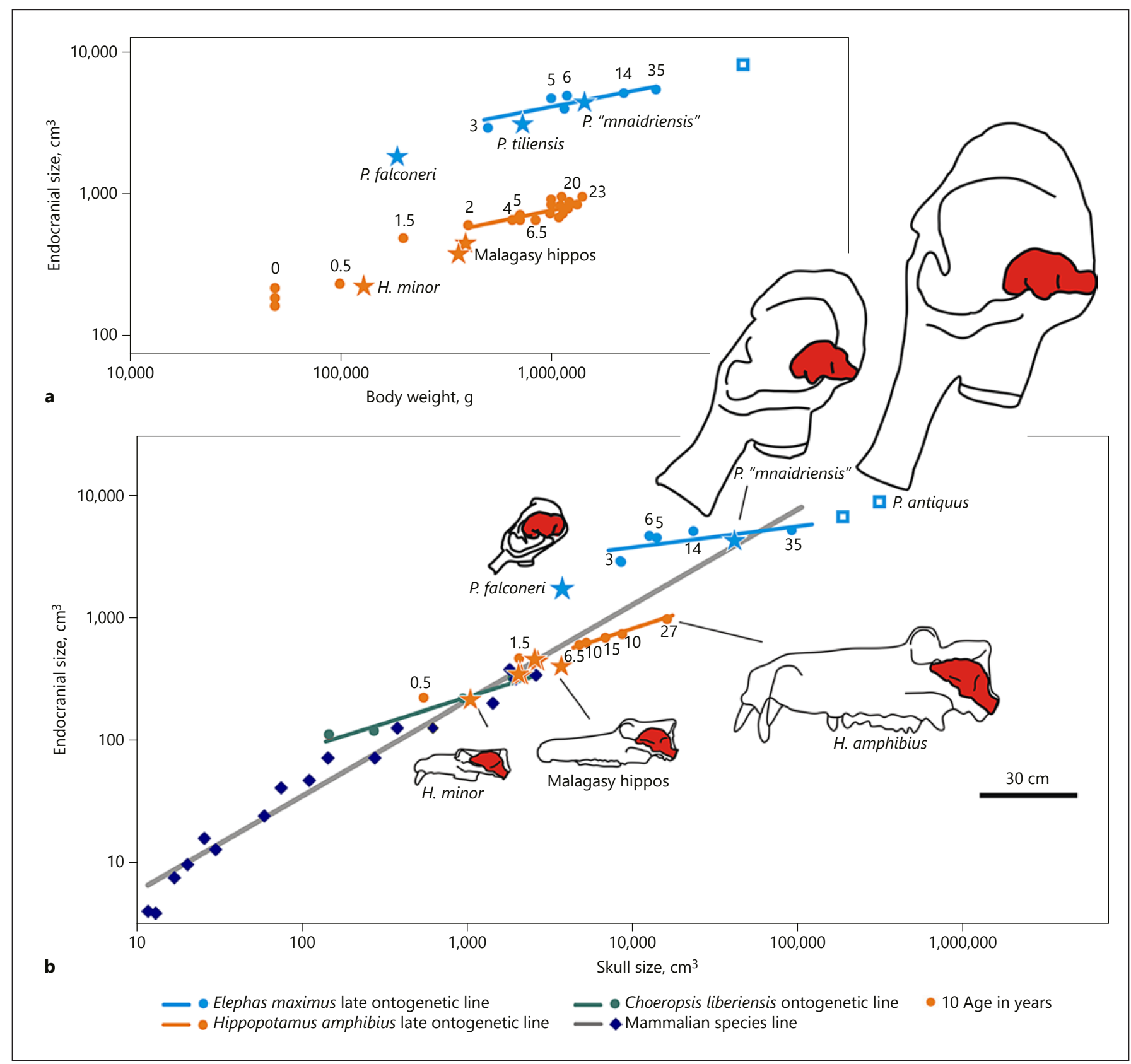

Fig. 6. Relationship between endocranial and cranial size. a Endocranial capacities of elephants and hippos plotted versus their cranial capacities. b Double-logarithmic plot of endocranial versus cranial capacities of insular dwarfs, Elephas maximus, Hippopota- mus amphibius, and Choeropsis liberiensis. Numbers indicate the age in years of Elephas and Hippopotamus individuals. All ages were determined by dental criteria. rasinghe [1998] should have weighed approximately $1,000 \mathrm{~kg}$. However, the BM of P. "mnaidriensis" is estimated to be $1,389 \mathrm{~kg}$ [Lomolino et al., 2013]. This suggests that $P$. "mnaidriensis" had a smaller brain than a juvenile Elephas of the same BM. The brain of P. falco- neri is comparatively even smaller. Its EV is just $1,800 \mathrm{~cm}^{3}$ [Accordi and Palombo, 1971], based on which the brM can be reconstructed at 1,595 g, following Benoit [2015], which is comparable to the brain of a newborn African elephant (approximately 1,600 g in Pagel and Harvey 
[1990]). However, a newborn Loxodonta weighs considerably less than an adult $P$. falconeri: A newborn Loxodonta has a BM of approximately $100 \mathrm{~kg}(95-112 \mathrm{~kg}$ in Dale [2010]), compared to the $189 \mathrm{~kg}$ of $P$. falconeri (Table 2). Therefore, P. falconeri has a smaller brain than a juvenile Loxodonta of the same body size.

Weston and Lister [2009] concluded that the brain size of the Malagasy dwarf hippos (H. lemerlei, H. madagascariensis) is smaller than predicted based on ontogenetic growth curves. My data confirm this for these 2 species but also for $H$. minor, which have a much smaller brain than predicted by the ontogenetic scaling of $\mathrm{H}$. amphibius.

The skull volume of $H$. minor is approximately 4 times the size of its brain volume (Fig. 5). This skull-brain ratio is considerably lower than that of adults of both extant hippo species but is observed in their juveniles. The skullbrain volume ratio of Malagasy dwarf hippos is comparable to that seen in C. liberiensis, but considerably smaller than that observed in H. amphibius (Fig. 5b). An adult male C. liberiensis (AMNH(M) 148452) has a skull approximately 7 times the size of its brain, while an adult $H$. amphibius (AMPG H.a.2) has a skull approximately 16 times larger than its brain.

\section{Discussion/Conclusion}

\section{Relative Brain Size among "All" Mammals and among} Each Family

Dwarf elephants have high EQ values. The Manger EQ increases from 1.12 in P. antiquus to 3.75 in P. falconeri. The Jerison EQ of $P$. falconeri is calculated here as 4.03 . The endocast of $P$. falconeri used for estimating its brM is from a female. Larramendi and Palombo [2015] estimated the $\mathrm{BM}$ of that particular female as $168 \mathrm{~kg}$. When this $\mathrm{BM}$ value is used then a slightly higher value of EQ is obtained (Manger EQ = 4.08; Jerison EQ = 4.36). Even higher EQ values are produced when lower estimates of body weight are taken into account. For example, Benoit [2015] used a BM of $81.3 \mathrm{~kg}$ published by Palombo and Giovinazzo [2005] and indicated a Jerison EQ 6.62. Nevertheless, in all calculations, the encephalization of $P$. falconer $i$ is significantly higher than that of any mainland elephant. In most mammalian orders, there is a strict correlation between brM and BM [Boddy et al., 2012]. P. falconeri does not follow this rule. As shown in Figure 3b, P. falco$n e r i$ is an outlier when it comes to relative brain size. No other insular mammal has a brain that differs so much from that of its mainland relatives.

The Brain of Insular Elephants and Hippos
The slope for the allometric trend among continental elephants is 0.138 (Fig. 4a). Such a value, although rather shallow, is within the range of slope values of mammalian families (Fig. 4e). Thus, although insular elephants have relatively larger brains than their mainland ancestors, their brains are smaller than what is predicted by the allometric relationship among their continental relatives. The brain of $P$. "mnaidriensis" is $13 \%$, of $P$. tilensis is nearly $30 \%$, and that of $P$. falconeri $52 \%$ smaller than what is predicted by the Elephantidae allometric relationship.

The African hippopotamus, $H$. amphibius has the smallest relative brain size of all contemporary ungulates [Radinsky, 1987]. The results of the present study indicate that the relative brain size of insular hippopotamuses is slightly larger than that of $H$. amphibius (Manger EQ 0.41 ). The Manger EQ of the Malagasy hippos is 0.51 for $H$. madagascariensis and 0.48 for H. lemerlei, whereas the smallest insular dwarf hippo, $H$. minor, has an even higher Manger EQ of 0.58 . However, when the brains of insular hippopotamuses are compared with the trend connecting the averages of 2 contemporary continental species, $H$. amphibius and C. liberiensis, a different pattern emerges. Although insular hippos have relatively larger brains than $H$. amphibius, their brains are smaller than what is predicted by the 2 living taxa combined (Fig. $3 b$ ). In short, insular hippos have an increasingly larger relative brain size during dwarfism, but do not reach the value of the continental dwarf hippo, C. liberiensis. This is because the slope of the line between the averages of each of 2 living hippo species is shallower than that defined for all mammals. That is an expected result as most allometric slopes are less steep among families than applied to "all" mammals, and slopes among genera are even less steep than among families [Martin and Harvey, 1985] although this could be partly due to statistical artifacts [see Pagel and Harvey, 1988].

The late Pleistocene-Holocene Balearic mouse-goat, M. balearicus, was reported as a case of extreme brain size reduction during phyletic dwarfing [Köhler and MoyàSolà, 2004]. Myotragus evolved in isolation on the Gymnesic Islands for more than 5 million years [Bover et al., 2008]. According to Köhler and Moyà-Solà [2004], the brain of the terminal species of this anagenetic lineage, $M$. balearicus, is approximately half the size of what is predicted based on the general trend for the contemporary mainland bovids. However, in order to evaluate the brain changes during phyletic dwarfing in Myotragus, one should compare it either with its direct mainland ancestor or with other late Miocene bovids. Myotragus is phyloge-

Brain Behav Evol 2018;92:167-181 177 
netically related to the Miocene archaic goats Aragoral and Norbertia [Rozzi, 2013]. There are only a few publications on the brains of late Miocene bovids, and, to my knowledge, none is on Aragoral and Norbertia. The Manger EQs of 3 other late Miocene taxa, Plesiaddax, Urmiatherium, and Miotragocerus, range from 0.57 to 0.67 (Fig. 2). With those encephalization values in mind, the brain of M. balearicus (Manger EQ 0.50) - although still smaller - does not reach the reported size reduction of $50 \%$ that was based on comparisons with modern species. On the other hand, it should be pointed out that modern bovids display a wide range of relative brain size (Manger EQ ranging from 0.56 to 1.39; data from Pérez-Barbería and Gordon [2005]). Five million years ago, bovids may have had a similarly wide encephalization range, and Aragoral and Norbertia may have had EQ values significantly different (that is, higher) than those of Plesiaddax, Urmiatherium, and Miotragocerus. Therefore, without direct information about the relative brain size of its ancestor, Myotragus should not be considered as a proven case of extreme brain size reduction.

Studies on 3 other insular dwarfs report no reduction in relative brain size either. The first is the Pleistocene Cretan deer Candiacervus, which was $46 \%$ the mass of Dama dama. Its relative brain size underwent only minor changes after its geographic isolation [Palombo et al., 2008]. The Manger EQ for C. ropalophorus $(E Q=1.32)$ is similar to that of $D$. dama $(\mathrm{EQ}=1.21)$.

Another phylogenetic dwarf is the late Pleistocene Sardinian dog, C. sardous, which was $49 \%$ of its ancestral mainland size [Lyras et al., 2010]. The relative brain size of $C$. sardous $(\mathrm{EQ}=1.3)$ is comparable to that of $L$. pictus $(\mathrm{EQ}=1.4)$ and higher than that of its ancestor, $X$. lycaonoides $(\mathrm{EQ}=1.0)$. Similarly, no noticeable change in relative brain size is seen in an extant insular canid, the gray fox of the Channel Islands of California, Urocyon littoralis, relative to its phylogenetic mainland ancestor $U$. cinereoargenteus [Schauber and Falk, 2008] (the BM of U. littoralis is $55-70 \%$ of its mainland relative [Lomolino et al., 2013]).

The island species which attracted the most attention on this subject is $H$. floresiensis. This hominid is considered by many as a descendant of $H$. erectus [e.g., Brown et al., 2004; Lyras et al., 2009, but see Argue et al., 2017]. The relative brain size of $H$. floresiensis is the same as that of $H$. erectus [Falk et al., 2005]. However, when compared with other hominids, $H$. floresiensis has an australopithecine-like brain/body size ratio [Falk et al., 2005]. Note, however, that according to the same authors, the relative brain size of $H$. floresiensis does not fall on the projected ontogenetic curve for relative brain size in $H$. erectus (see also below).

\section{Static Intraspecific Scaling Model}

According to Lande [1979], directional selection on both brain and body size could potentially lead to steeper allometric slopes. This is the case when evolutionary pressure is not only on body size reduction but also on other traits, such as brain size. The skulls of the 3 insular hippos as well as that of P. falconeri are not simply scale-down versions of mainland adults [van der Geer et al., 2018]. Particularly in the case of elephants, the contemporary species are all large sized, thus considerably different in size from $P$. falconeri. On the other hand, the skull shape of $P$. "mnaidriensis," a species that in size is somehow comparable to small-sized living elephants, did not change as dramatically as in P. falconeri [van der Geer et al., 2018]. According to the same study, it seems that during the first part of dwarfing, skull changes are smaller than during extreme dwarfing, which is in accordance with Lister's [1996] observation that, initially, dwarfism would be merely an allometric stunting process but that in the longer term, natural selection would produce further changes and adaptations under evolutionary pressures exerted by the local environment. The brain of $P$. "mnaidriensis" could fall in the latter category.

Based on intraspecific mammalian allometric relationships, Martin et al. [2006] claimed that the brain of $H$. floresiensis was too small to have been a dwarfed descendant of $H$. erectus. They applied a "typical mammalian" intraspecific scaling (with a scaling component of 0.25 ) and the intraspecific scaling of $H$. sapiens. Indeed, the brain of $H$. floresiensis cannot be explained under such type of scaling. However, as observed in insular hippos and in P. falconeri, intraspecific scaling does not always explain the brain changes during dwarfing.

\section{Ontogenetic Intraspecific Scaling Model}

The brains of the 2 Malagasy hippos, $H$. madagascariensis and $H$. lemerlei, were examined by Weston and Lister [2009] from an ontogenetic perspective. They examined whether the brain of the Malagasy hippos scales allometrically along the ontogenetic curve predicted for their mainland relative. In particular, they applied a "late ontogenetic scaling" (for hippos older than 2 years resulting in a slope of 0.35) and "ontogenetic scaling" (for all ages of hippos resulting in a slope of 0.47 ). In both cases, they found that the brain of both Malagasy hippos is smaller than predicted under ontogenetic models. In 
their study, Weston and Lister [2009] used skull size instead of BM (see Materials and Methods section). To calculate skull size, they used 3 linear measurements, length, height, and width of each skull. Since they were dealing only with hippos, this was an accurate method. However, since I examined more taxa here, the volume of each skull was measured with a more accurate method (see Materials and Methods). As shown in Figure 6, Malagasy hippos as well as the Cypriot hippo have brains smaller than predicted under the ontogenetic model, which is in line with the findings of Weston and Lister [2009].

The encephalization of $P$. falconeri is significantly higher than that of any mainland elephant, which makes P. falconeri an outlier when it comes to relative brain size. Palombo [2001] and Larramendi and Palombo [2015] considered this as a paedomorphic trait. Indeed, an elephant neonate brain is $50 \%$ of its adult brain weight, and juvenile elephants have relatively larger brains than adults do [Shoshani et al., 2006]. However, Weston and Lister [2009] applied their ontogenetic model derived from hippos (see above) and concluded that the brain of P. falconeri is smaller than the predicted values. The data presented here show that the brains of $P$. "mnaidriensis," $P$. tiliensis, and P. falconeri are smaller than those of juvenile E. maximus individuals of the same skull size and body size. Therefore, the brain size of insular Palaeoloxodon species does not scale allometrically along the ontogenetic curve predicted for E. maximus. One could, correctly, argue that insular Palaeoloxodon species should be compared with the ontogenetic trajectory of $P$. antiquus and not with that of $E$. maximus. However, although this is a valid argument, such a comparison cannot take place, as there are no known endocasts of juvenile P. antiquus.

In Hippopotamus, the contribution of the brain volume to the total skull volume increases from $6 \%$ in mainland $H$. amphibius to $25 \%$ in the dwarf species $H$. minor. At the same time, the muzzle decreases in volume (gets shorter, see van der Geer et al., [2018]). In elephants, the large-sized mainland Palaeoloxodon has its brain deeply embedded in its skull. The pneumatic bones around the brain are so extensive that the brain practically does not influence the shape of the skull. In the case of P. falconeri, however, the endocranial cavity constitutes almost half of the total skull volume, thus influencing the overall aspect of the skull.

Falk et al. [2005] indicated that $H$. floresiensis may not be an insularly dwarfed descendent of $H$. erectus, because the relative brain size of $H$. floresiensis does not coincide with the projected ontogenetic curve for relative brain size in $H$. erectus. However, the phylogenetic value of this observation remains doubtful, since data presented here suggest that insular dwarfing does not necessarily comply with predictions based on the ontogenetic scaling.

\section{Conclusion}

Dwarf elephants have high EQ values. Their EQ value increases with the degree of size reduction. Palaeoloxodon falconeri, being the smallest insular elephant, has the highest EQ. No other insular mammal has a brain that differs so much in relative size from that of its mainland relatives. Nevertheless, small-sized insular elephants have brains that are smaller than what is predicted by the allometric relationship among their continental relatives. Furthermore, their brain does not scale allometrically along the ontogenetic curve predicted for E. maximus.

Hippopotamuses have relatively low EQ values. The EQ values of insular hippos are slightly higher than those of their continental relative, $H$. amphibius, but smaller than those of C. liberiensis. Malagasy hippos (H. madagascariensis and H. lemerlei) as well as the Cypriot hippo ( $H$. minor) have brains smaller than that predicted under the ontogenetic and static models of $H$. amphibius. Data on 3 other insular dwarfs (C. ropalophorus, C. sardous, Urocyon littoralis) indicate no reduction in relative brain size.

Insular dwarfs are not simple scale-down models of their mainland ancestors. Particularly in the case of the smaller dwarfs, their skeletal morphology, although it still resembles that of their mainland relatives, has many new features and extends beyond that seen in their mainland relatives. Their brain can follow scaling patterns that differ essentially from that of their mainland relatives.

\section{Acknowledgment}

I thank Ross MacPhee, Neil Duncan, Jin Meng, and Judy Galkin (AMNH), Carolina di Patti (MGG), Spyridoula Pappa, and Pip Brewer (NHM), Christine Argot (MNHN), Frieder Mayer (MFN), Vassilis Karakitsios (AMPG), Jelle Reumer, and Paul Lambers (MUU) for allowing me to digitize specimens and to measure EV of skulls in their care. Bartholomeus van der Geer helped me with the data collection. The insightful comments and corrections made by 2 anonymous reviewers considerably improved the manuscript.

\section{Statement of Ethics}

The author has no ethical conflicts to disclose. 


\section{Disclosure Statement}

The author has no conflicts of interest to declare.

\section{Funding Sources}

This research received support from the SYNTHESYS Project (GB-TAF-6355 and FR-TAF-6549).

\section{References}

Accordi FS, Palombo MR. Morfologia endocranica degli elephanti nani pleistocenici de Spinagallo (Siracusa) e comparazione con l'endocranio de Elephas antiquus. Rendiconti Accademia Nazionale Lincei (Ser 8) 1971; 51:111-24.

Anthony J. Étude de moulages endocrâniens d'hippopotames disparus. Mem Mus Natl Hist Nat. 1948;26:31-56.

Argue D, Groves CP, Lee MS, Jungers WL. The affinities of Homo floresiensis based on phylogenetic analyses of cranial, dental, and postcranial characters. J Hum Evol. 2017 Jun; 107: $107-33$.

Bauchot R, Stephan H. Encéphales et moulages endocrâniens de quelques insectivores et primates actueles. Lehman J-P, editor. Problèmes Actuels de Paléontologie (Evolution des Vertébrés). Coll Int Centre Natl Rech Sci. 1967;163:575-87.

Benoit J. A new method of estimating brain mass through cranial capacity in extinct proboscideans to account for the non-neural tissues surrounding their brain. J Vertebr Paleontol. 2015;35(6):e991021.

Boddy AM, McGowen MR, Sherwood CC, Grossman LI, Goodman M, Wildman DE. Comparative analysis of encephalization in mammals reveals relaxed constraints on anthropoid primate and cetacean brain scaling. J Evol Biol. 2012 May;25(5):981-94.

Boekschoten GJ, Sondaar PY. On the fossil mammalia of Cyprus, I and II. Proc K Ned Akad Wet Ser B. 1972;75(4): 306-38.

Boisserie JR. The phylogeny and taxonomy of Hippopotamidae (Mammalia: Artiodactyla): a review based on morphology and cladistic analysis. Zool J Linn Soc. 2005;143(1):1-26.

Bover P, Quintana J, Alcover JA. Three islands, three worlds: paleogeography and evolution of the vertebrate fauna from the Balearic Islands. Quat Int. 2008;182(1):135-44.

Brown P, Sutikna T, Morwood MJ, Soejono RP, Jatmiko, Saptomo EW, et al. A new small-bodied hominin from the Late Pleistocene of Flores, Indonesia. Nature. 2004Oct;431(7012): 1055-61.

Dale RH. Birth statistics for African (Loxodonta africana) and Asian (Elephas maximus) elephants in human care: history and implications for elephant welfare. Zoo Biol. 2010; 29(2):87-103.

Edinger T. Evolution of the horse brain. Geol Soc Am. 1948;25:1-177.

Falk D, Hildebolt C, Smith K, Morwood MJ, Sutikna T, Brown P, et al. The brain of LB1, Homo floresiensis. Science. 2005 Apr;308 (5719):242-5.
Ferretti MP. The dwarf elephant Palaeoloxodon mnaidriensis from Puntali Cave, Carini (Sicily; late Middle Pleistocene): Anatomy, systematics and phylogenetic relationships. Quat Int. 2008;182(1):90-108.

Fovet W, Faure M, Guerin C. Hippopotamus guldbergi n. sp.: révision du statut d' Hippopotamus madagascariensis Guldberg, 1883, après plus d'un siècle de malentendus et deconfusions taxonomiques. Zoosystema. 2011; 33(1):61-82.

Goodman SM, Jungers WL. Extinct Madagascar: Picturing the Island's Past. Chicago: University of Chicago Press; 2014. https://doi.org/ 10.7208/chicago/9780226156941.001.0001.

Herridge VL. Dwarf elephants on Mediterranean islands: a natural experiment in parallel evolution [ $\mathrm{PhD}$ thesis]. London: University College; 2010.

Houtekamer JL, Sondaar PY. Osteology of the fore limb of the Pleistocene dwarf hippopotamus from Cyprus with special reference to phylogeny and function. Proc K Ned Akad Wet Ser B 1979;82(4): 411-448.

Jerison HJ. Evolution of the brain and intelligence. New York: Academic Press; 1973.

Jorstad A, Nigro B, Cali C, Wawrzyniak M, Fua P, Knott G. NeuroMorph: a toolset for the morphometric analysis and visualization of $3 \mathrm{D}$ models derived from electron microscopy image stacks. Neuroinformatics. 2015 Jan;13(1): 83-92.

Köhler M, Moyà-Solà S. Reduction of brain and sense organs in the fossil insular bovid Myotragus. Brain Behav Evol. 2004;63(3):125-40.

Kubo D, Kono RT, Kaifu Y. Brain size of Homo floresiensis and its evolutionary implications. Proc Biol Sci. 2013 Apr 17;280(1760):20130338.

Kurt F, Kumarasinghe JC. Remarks on body growth and phenotypes in Asian elephant Elephas maximus. Acta Theriol (Warsz). 1998; 43 Suppl 5:135-53.

Lande R. Quantitative genetic analysis of multivariate evolution, applied to brain: body size allometry. Evolution. 1979 Mar;33(1Part2):402-16.

Larramendi A, Palombo MR. Body size, structure, biology and encephalization quotient of Palaeoloxodon ex gr. P. falconeri from Spinagallo Cave (Hyblean plateau, Sicily). Hystrix It J Mamm. 2015;26(2):102-9.

Laws RM. Dentition and ageing of the Hippopotamus. E Afr Wildl J. 1968;6:19-52.

Lazaridis GT, Kostopoulos D, Lyras G, Roussiakis S. A new Late Miocene ovibovine like bovid (Bovidae, Mammalia) from the Kassandra Peninsula (Chalkidiki, Northern Greece) and implications to the phylogeography of the group. Paläontol Z. 2017;91(3):427-37.
Lister AM. Dwarfing in island elephants and deer: processes in relation to time of isolation. Symp Zool Soc Lond. 1996;69:277-92.

Lomolino MV, van der Geer AA, Lyras GA, Palombo MR, Sax DF, Rozzi R. Of mice and mammoths: generality and antiquity of the island rule. J Biogeogr. 2013;40(8):1427-39.

Lyras GA. The evolution of the brain in Canidae (Mammalia: carnivora). Scr Geol. 2009;139: $1-93$.

Lyras GA, Dermitzakis MD, van der Geer AA, van der Geer SB, de Vos J. The origin of Homo floresiensis and its relation to evolutionary processes under isolation. Anthropol Sci. 2009;117(1):33-43.

Lyras GA, van der Geer AA, Rook L. Body size of insular carnivores: evidence from the fossil record. J Biogeogr. 2010;37(6):1007-21.

Lyras GA, van der Geer AE, Dermitzakis M, de Vos J. Cynotherium sardous, an insular canid (Mammalia: Carnivora) from the Pleistocene of Sardinia (Italy), and its origin. J Vertebr Paleontol. 2006;26(3):735-45.

Maccagno AM. Gli elefanti fossili di Riano (Roma). Geol Rom. 1962;1:33-132.

Macrini TE, Rougier GW, Rowe T. Description of a cranial endocast from the fossil mammal Vincelestes neuquenianus (Theriiformes) and its relevance to the evolution of endocranial characters in therians. Anat Rec (Hoboken). 2007 Jul;290(7):875-92.

Maglio V. Origin and Evolution of the Elephantidae. Trans Am Philos Soc. 1973;63(3):1-149.

Manger PR. An examination of cetacean brain structure with a novel hypothesis correlating thermogenesis to the evolution of a big brain. Biol Rev Camb Philos Soc. 2006 May;81(2): 293-338.

Marino L. Brain growth in the harbor porpoise (Phocoena phocoena) and Pacific white-sided dolphin (Lagenorhynchus obliquidens). J Mammal. 1999;80:1353-60.

Martin RB. The Transboundary Mammal Project of the Ministry of Environment and Tourism, Namibia. Windhoek: The Namibia Nature Foundation; 2005. p. 74.

Martin RD. Relative brain size and basal metabolic rate in terrestrial vertebrates. Nature. 1981 Sep;293(5827):57-60.

Martin RD, Harvey PH. Brain size allometry: ontogeny and phylogeny. In: Jungers WL, editor. Size and scaling in primate biology. New York: Springer; 1985. p. 147-73.

Martin RD, Maclarnon AM, Phillips JL, Dussubieux L, Williams PR, Dobyns WB. Comment on "The Brain of LB1, Homo floresiensis". Science 2006 May; 19:312(5776): 999. 
Meyer M, Palkopoulou E, Baleka S, Stiller M, Penkman KE, Alt KW, et al. Palaeogenomes of Eurasian straight-tusked elephants challenge the current view of elephant evolution. eLife. 2017 Jun;6:e25413.

Montgomery SH. Primate brains, the 'island rule and the evolution of Homo floresiensis. J Hum Evol. 2013 Dec;65(6):750-60.

Osborn HF. Palaeoloxodon antiquus italicus sp. nov., final stage in the 'Elephas antiquus' phylum. Am Mus Novit. 1931;460:1-24.

Pagel MD, Harvey PH. Diversity in the brain sizes of newborn mammals. Bioscience. 1990; 40(2):116-22.

Pagel MD, Harvey PH. The taxon-level problem in mammalian brain size evolution: facts and artefacts. Am Nat. 1988;132:344-59.

Palkopoulou E, Lipson M, Mallick S, Nielsen S, Rohland N, Baleka S, et al. A comprehensive genomic history of extinct and living elephants. Proc Natl Acad Sci USA. 2018 Mar; 115(11):E2566-74.

Palombo MR, Giovinazzo C. Elephas falconeri from Spinagallo Cave (south-eastern Sicily, Hyblean Plateau, Siracusa): a preliminary report on brain to body weight comparison. Monografies de la Societat d'Historia Natural de les Balears. 2005;12:255-64.

Palombo MR, Köhler M, Moyà-Solà S, Giovinazzo C. Brain versus body mass in endemic ruminant artiodactyls: A case studied of Myotragus balearicus and smallest Candiacervus species from Mediterranean Islands. Quat Int. 2008;182(1):160-83.

Palombo MR. Paedomorphic features and allometric growth in the skull of Elephas falconeri from Spinagallo (Middle Pleistocene, Sicily). In: Cavaretta G, Gioia P, Mussi M, Palombo MR, editors. The World of Elephants. Proceedings of the First International Congress, Rome, 16-20 October. Roma: CNR; 2001. p. 492-6.

Pérez-Barbería FJ, Gordon IJ. Gregariousness increases brain size in ungulates. Oecologia. 2005 Aug;145(1):41-52.
Pyka M, Hertog M, Fernandez R, Hauke S, Heider D, Dannlowski U, et al. fMRI data visualization with BrainBlend and Blender. Neuroinformatics. 2010 Mar;8(1):21-31.

Radinsky LB. The Evolution of Vertebrate Design. Chicago, London: The University of Chicago Press; 1987.

Röhrs M, Ebinger P. Welche quantitativen Beziehungen bestehen bei Säugetieren zwischen Schädelkapazität und Hirnvolumen? Mamm Biol. 2001;66:102-10.

Roth VL, Shoshani J. Dental identification and age determination in Elephas maximus. J Zool (Lond). 1988;214(4):567-88.

Roth VL. How elephants grow: heterochrony and the calibration of developmental stages in some living and fossil species. J Vertebr Paleontol. 1984;4(1):126-45.

Rozzi R. Palaeobiogeography and evolution of insular bovids: ecogeographic patterns of body mass variation and morphological changes [unpublished $\mathrm{PhD}$ thesis]. Roma: Università degli Studi di Roma La Sapienza, Dipartimento di Scienze sella Terra; 2013.

Schauber A, Falk D. Proportional dwarfism in foxes, mice, and humans: implications for relative brain size in Homo floresiensis. Am J Phys Anthropol. 2008;Suppl 46:185-6.

Shoshani J, Ferretti MP, Lister AM, Agenbroad D, Saegusa H, Mol D, et al. Relationships within the Elephantinae using hyoid characters. Quat Int. 2007;169-170:174-85.

Shoshani J, Kupsky WJ, Marchant GH. Elephant brain. Part I: gross morphology, functions, comparative anatomy, and evolution. Brain Res Bull. 2006 Jun;70(2):124-57.

Smith FA, Lyons SK, Ernest SK, Jones KE, Kaufman DM, Dayan T, et al. Body mass of late Quaternary mammals. Ecology. 2003;84 (12):3403

Spassov N, Geraads D. Tragoportax Pilgrim, 1937 and Miotragocerus Stromer, 1928 (Mammalia, Bovidae) from the Turolian of Hadjidimovo, Bulgaria, and a revision of the late Miocene Mediterranean Boselaphini. Geodiversitas. 2004;26(2):339-70.

Stankwich T, Romero AN. The correlated evolution of antipredator defences and brain size in mammals. Proc Biol Sci. 2017 Jan 11;284 (1846):20161857.
Stuenes S. Taxonomy, habits, and relationships of the subfossil Madagascan Hippopotami Hippopotamus lemerlei and $H$. madagascariensis. J Vertebr Paleontol. 1989;9(3):241-68.

van den Bergh GD, Kaifu Y, Kurniawan I, Kono RT, Brumm A, Setiyabudi E, et al. Homo floresiensis-like fossils from the early Middle Pleistocene of Flores. Nature. 2016 Jun;534 (7606):245-8.

van der Geer AAE. Uniformity in variety: Antler morphology and evolution in a predator-free environment. Palaeontol Electron. 2018. Available from: https://palaeo-electronica.org/ content/2018/2159-uniformity-in-variety.

van der Geer AAE, de Vos J, Lyras G, Drinia H. Morphology of articular surfaces can solve a phylogenetic issue: one instead of two ancestors for Candiacervus (Mammalia: Cervoidea). Zitteliana / B. 2013;31:33-4.

van der Geer A, Lyras G, De Vos J, Dermitzakis M. Evolution of Island Mammals: Adaptation and Extinction of Placental Mammals on Islands. Oxford: Wiley-Blackwell; 2010. https:// doi.org/10.1002/9781444323986.

van der Geer AAE, Lyras GA, Mitteroecker P, MacPhee RD. From Jumbo to Dumbo: cranial shape changes in elephants and hippos during phyletic dwarfing. Evol Biol. 2018; 45(3):303-17.

van der Geer AAE, Lyras GA, van den Hoek Ostende LW, de Vos J, Drinia H. A dwarf elephant and a rock mouse on Naxos (Cyclades, Greece) with a revision of the palaeozoogeography of the Cycladic Islands (Greece) during the Pleistocene. Palaeogeogr Palaeoclimatol Palaeoecol. 2014;404:133-44.

Weston EM, Lister AM. Insular dwarfism in hippos and a model for brain size reduction in Homo floresiensis. Nature. 2009 May;459 (7243):85-8.

Weston EM. A biometrical analysis of evolutionary change within the Hippopotamidae $[\mathrm{PhD}$ thesis]. Cambridge: University of Cambridge; 1988. 